\title{
Catalytic Chemical Vapor Deposition Synthesis of Carbon Aerogels of High-Surface Area and Porosity
}

\author{
Armando Peña, ${ }^{1}$ Julio Puerta, ${ }^{1,2}$ Aimé Guerrero, ${ }^{3}$ Edgar Cañizales, ${ }^{4}$ and Joaquín L. Brito ${ }^{5}$ \\ ${ }^{1}$ Laboratorio de Física de Plasma y Nanotecnología, Universidad Simón Bolivar, Apartado 89000, Caracas 1080, Venezuela \\ ${ }^{2}$ Departamento de Física, Universidad Simón Bolívar, Apartado 89000, Caracas 1080, Venezuela \\ ${ }^{3}$ Departamento de Ciencias de los Materiales, Universidad Simón Bolivar, Apartado 89000, Caracas 1080, Venezuela \\ ${ }^{4}$ PDVSA-Intevep, Los Teques, Apartado 76343, Caracas 1070-A, Venezuela \\ ${ }^{5}$ Centro de Química, Instituto Venezolano de Investigaciones Científicas, Apartado 20632, Caracas 1020, Venezuela
}

Correspondence should be addressed to Julio Puerta,jpuerta@usb.ve

Received 16 March 2012; Revised 28 August 2012; Accepted 28 August 2012

Academic Editor: Tanaji P. Gujar

Copyright (c) 2012 Armando Peña et al. This is an open access article distributed under the Creative Commons Attribution License, which permits unrestricted use, distribution, and reproduction in any medium, provided the original work is properly cited.

In this work carbon aerogels were synthesized by catalytic chemical vapor deposition method (CCVD). Ferrocene were employed as a source both of catalytic material (Fe) and of carbon. Gaseous hydrogen and argon were used as reductant and carrier gas, respectively. The products of reaction were collected over alumina. The morphology and textural properties of the soot produced in the reaction chamber were investigated using Scanning Electron Microscopy, High-Resolution Transmission Electron Microscopy, $\mathrm{X}$-ray photoelectron spectroscopy, and $\mathrm{N}_{2}$ physisorption (BET and $\mathrm{BHJ}$ methods). After the evaluation of the porous structure of the synthesized products, $780 \pm 20 \mathrm{~m}^{2} / \mathrm{g}$ of $S_{\mathrm{BET}}$ and $0.55 \pm 0.02 \mathrm{~cm}^{3} / \mathrm{g}$ of $V_{\mathrm{BJH}}$ were found. The presence of iron carbide and the partial oxidation of carbon nanostructures were revealed by XPS.

\section{Introduction}

The fabrication of carbon nanostructures with characteristic morphologies will determine further applications such as field emitters, gas storage $\left(\mathrm{H}_{2}\right.$ for fuel cells), sensors, and biosensors, and so forth [1]. The high capacity of adsorption, chemical inertia, and the easy regenerability that have the carbon nanostructures make them potential useful adsorbents [2].

Carbon aerogels are nanostructured porous materials consisting in a network of carbonaceous particles of uniform nanosized dimensions, with superficial areas that commonly are found between 400 and $1100 \mathrm{~m}^{2} / \mathrm{g}$ and an electric conductivity of approximately $1000 \mathrm{~A} / \mathrm{cm}$. They are highly demanded in scientific technology: the most important applications of these carbonaceous structures are as electrodes and supercapacitors, where they serve as support for metal nanoparticles $[3,4]$.

Carbon aerogels are usually synthesized by hightemperature pyrolysis of organic aerogels, which in turn are prepared by polymerization of two monomers (e.g., resorcinol-formaldehyde) using sol-gel methods and processing the resulting material under supercritical conditions $[5,6]$. This type of synthesis involves several steps under very diverse conditions. Thus, a simpler preparation way would be an important advance in the synthesis of this kind of materials. Chemical Vapor Deposition (CVD) from hydrocarbon gaseous compounds or carbon monoxide is a relatively simple synthesis method that has been employed for the growth of carbon nanostructures [7]. When using metallic nanoparticles as catalytic sites for the growth of such carbon nanomaterials, it has been described as Catalytic CVD (CCVD) [8]. In particular, it has been proposed as a method for growing carbon nanotubes and filaments within the porous structure of conventionally prepared carbon aerogels $[9,10]$.

In this context, the objective of this work is to apply the technique of CCVD, employing a single organometallic compound, ferrocene $\left[\mathrm{Fe}\left(\mathrm{C}_{5} \mathrm{H}_{5}\right)_{2}\right]$, as source of both the catalyst and of carbon and a continuous flow reaction system with two separated heating zones. 


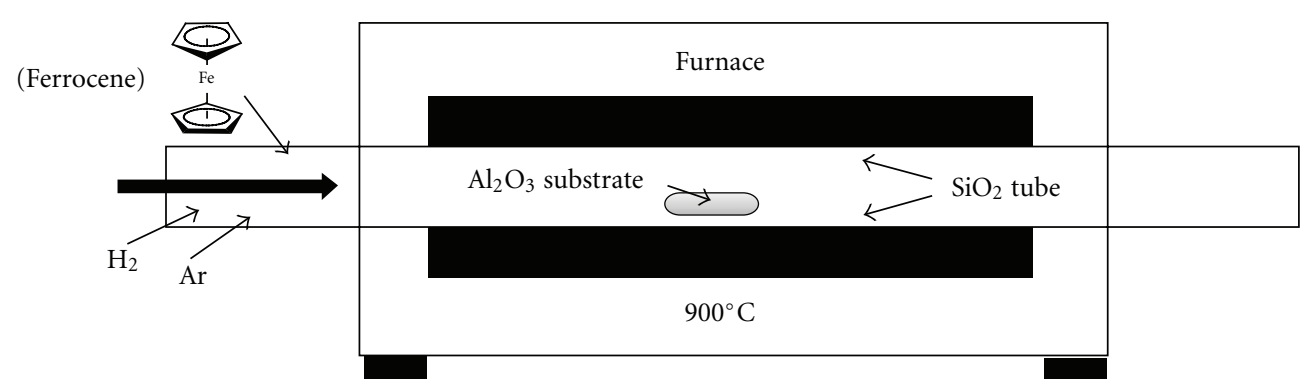

FIGURE 1: CVD reactor scheme employed the synthesis of the carbon aerogels.

\section{Experimental Setup}

In order to synthesize the aerogels, ferrocene was used as a simultaneous source of catalytic material $(\mathrm{Fe})$ and filler material (C). Gaseous hydrogen was employed as reductant, while argon was an inert carrier gas. The reaction products were collected onto either alumina or silica substrates.

A reaction chamber similar to that described previously [11] was employed. The ferrocene was sublimated in a preheating chamber, which temperature was set at $150^{\circ} \mathrm{C}$ and was transported to the cracking reactor by a flow of $\mathrm{H}_{2}$ and Ar. In total, $150 \mathrm{mg}$ of ferrocene was evaporated, in two consecutive steps of $100 \mathrm{mg}$ and $50 \mathrm{mg}$, with $10 \mathrm{~min}$ in between. The pyrolysis temperature in the cracking furnace was $900^{\circ} \mathrm{C}$, and the total gas flow was $10 \mathrm{~mL} / \mathrm{min}$ with a composition of $1: 1 \mathrm{v} / \mathrm{v}$ of $\mathrm{Ar}: \mathrm{H}_{2}$.

In order to eliminate $\mathrm{Fe}$ from the products, concentrated $\mathrm{HCl}$ and sonication were used. The resulting materials were characterized using Scanning Electronic Microscopy (SEM) with a JEOL scanning microscope, model JSM-6390, $30 \mathrm{KV}$; High Resolution Transmission Electronic Microscopy (HRTEM) with a JEOL transmission microscopy, model JEM-2100, 200 KV; X-ray Photoelectron Spectroscopy (XPS) with a Thermo Scientific VG-Escalab 220i-XL; $\mathrm{N}_{2}$ physisorption with a Micrometrics Surface Analyzer, model ASAP 2000, using the BET and $\mathrm{BJH}$ methods for the textural analysis. In Figure 1 a schematic drawing of the CVD homemade reactor and experimental conditions is presented.

\section{Results and Discussion}

In Figure 2(a), three SEM micrographies of the synthesized carbon aerogel at different magnifications are shown, in which a network of carbon nanotubes and nanospheres can be observed. At the lower magnification, nanotubes foam clusters deposited on a $\mathrm{SiO}_{2}$ substrate can be observed, while in the 5000x and 10000x micrographies the network of carbon nanotubes coated with nanospheres of carbon nanoparticles is clearly appreciated. The composition of these structures was determined by means of a chemical analysis by EDX in the same microscope, finding only C, $\mathrm{Fe}$ and $\mathrm{O}$ in weight percentages of $72.10 ; 26.84 ; 1.06 \%$, respectively (see Figure 2(b)). The presence of oxygen could be attributed to surface oxidation of Fe nanoparticles due to exposition to the atmosphere when samples are removed from the CVD reactor. Carbon aerogel grew evenly across the surface of $\mathrm{SiO}_{2}$.

In Figure 3, four HRTEM micrographies of the synthesized carbon aerogel are shown in which it can be seen a network of carbonaceous structures, such as nanotubes and nanospheres (see micrographs (a) and (b)). In the micrographs (c) and (d), consecutive increases of (b) are shown, where it can be seen on average $40 \mathrm{~nm}$ diameter carbon nanospheres.

XPS tests revealed the presence of iron carbide and partial oxidation of carbon nanostructures. XPS spectra of carbon aerogels in the $\mathrm{C} 1 s$ and $\mathrm{Fe} 2 p$ regions are presented in Figures 4(a) and 4(b), respectively. In the first one, we see three peaks with binding energies (BEs) of 286, 284 , and $280 \mathrm{eV}$, corresponding to the $s p 3 \mathrm{C}-\mathrm{C}$ bonds of tetrahedral structures, $\mathrm{C}-\mathrm{C} s p 2$ of graphitic structures, and $\mathrm{Fe}_{3} \mathrm{C}$, respectively [12-14]. The peak of iron carbide is displaced to a lower BE as compared to other reports $(283 \mathrm{eV}$ $[13,15])$, this large shift of about $3 \mathrm{eV}$ can be attributed to interactions with the magnetic field of nanoparticles of $\mathrm{Fe}$ or inefficient electrical connection that may exist between $\mathrm{Fe}$ and $\mathrm{C}$ atoms $[14,16]$. A fourth peak that appears around $278 \mathrm{eV}$ in the $\mathrm{C} 1 s$ region, which is denoted by the symbol $\psi$, can be attributed to the fullerene carbon filaments [17].

In the $\mathrm{Fe} 2 p$ region there are three peaks with BEs of 712,720 , and $726 \mathrm{eV}$. The 712 and 726 signals correspond to the $2 p_{3 / 2}$ and $2 p_{1 / 2} \mathrm{Fe}^{3+}$ species, respectively, while the intermediate signal is due to a satellite of the same species [18].

In Figure 5, the $\mathrm{N}_{2}$ adsorption isotherm at $77 \mathrm{~K}$ of the synthesized carbon aerogel can be observed. It is of type IV in the IUPAC/Brunauer-Emmett-Teller classifications, typical of mesoporous materials [19]. Given the very low increase of physisorbed volume below $P / P_{0} 0.05$, it can be deduced that the microporous volume is negligible in this sample. In the high-pressure region it appears a $\mathrm{H}_{3}$ hysteresis loop at a relative pressure higher than 0.8 . This indicates the existence of extraparticle large mesopores which could be formed between interconnected carbon nanoparticles [20]. After evaluating the pore structure of synthesized products by $\mathrm{BET}$ and $\mathrm{BJH}$ procedures, it is found a BET surface area, $S_{\mathrm{BET}}$, of $780 \pm 20 \mathrm{~m}^{2} / \mathrm{g}$ and $\mathrm{BJH}$ pore volume, $V_{\mathrm{BJH}}$, of $0.55 \pm 0.02 \mathrm{~cm}^{3} / \mathrm{g}$. The measured surface area is quite large for a non-microporous material.

Ferrocene has been frequently employed as a precursor of iron catalysts for the CVD synthesis of carbon nanotubes 

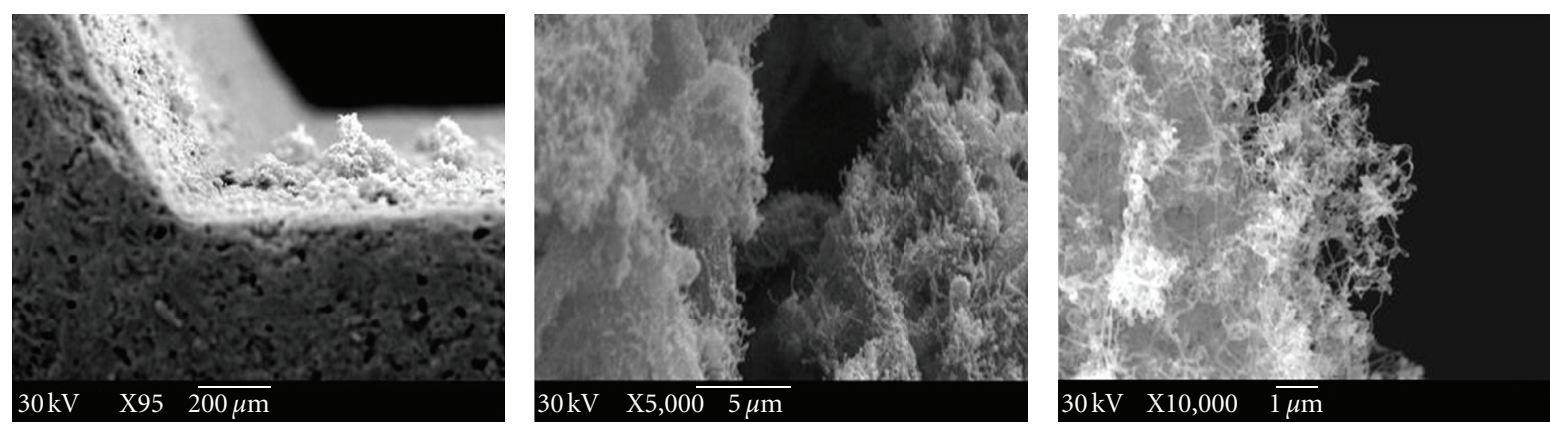

(a)

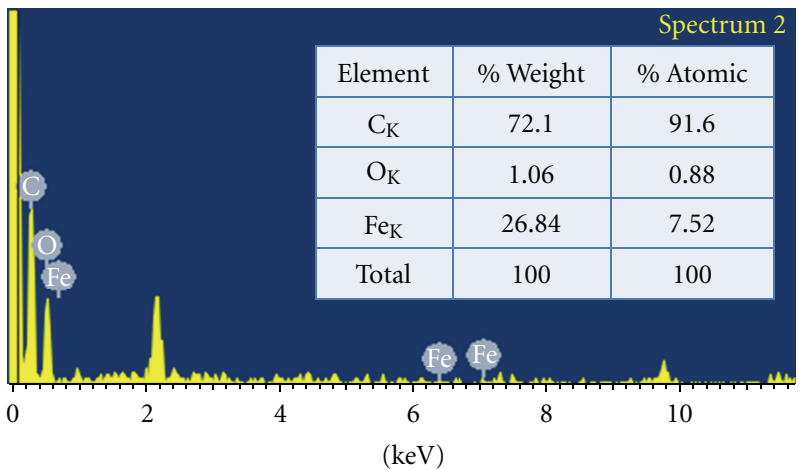

Full scale 110 cts cursor: 0.084 (1020cts)

(b)

Figure 2: (a) SEM micrographies of carbon aerogels on $\mathrm{SiO}_{2}$, at 95x, 5000x, and 10000x. (b) EDX spectrum of carbon aerogels. $\mathrm{K}_{\alpha}$ characteristics peaks are observed for $\mathrm{C}, \mathrm{O}$, and $\mathrm{Fe}$.

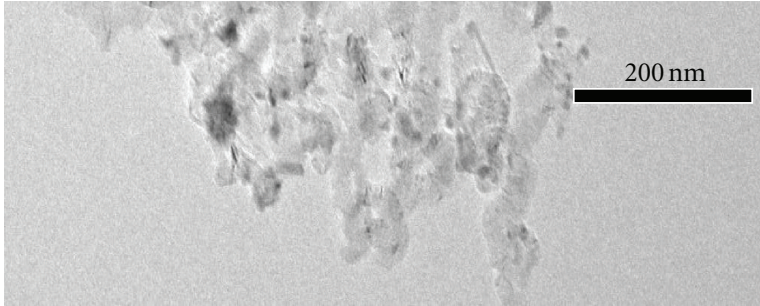

(a)

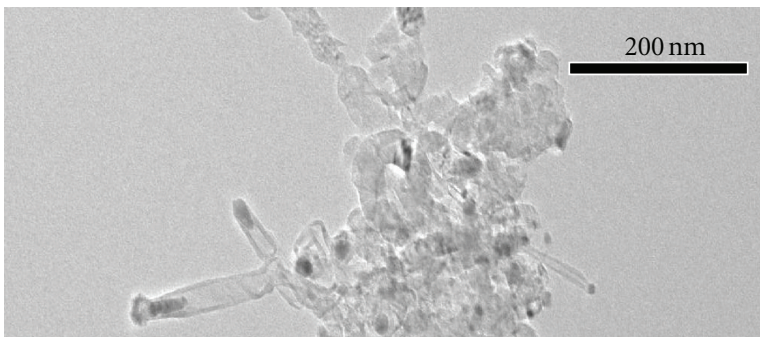

(b)

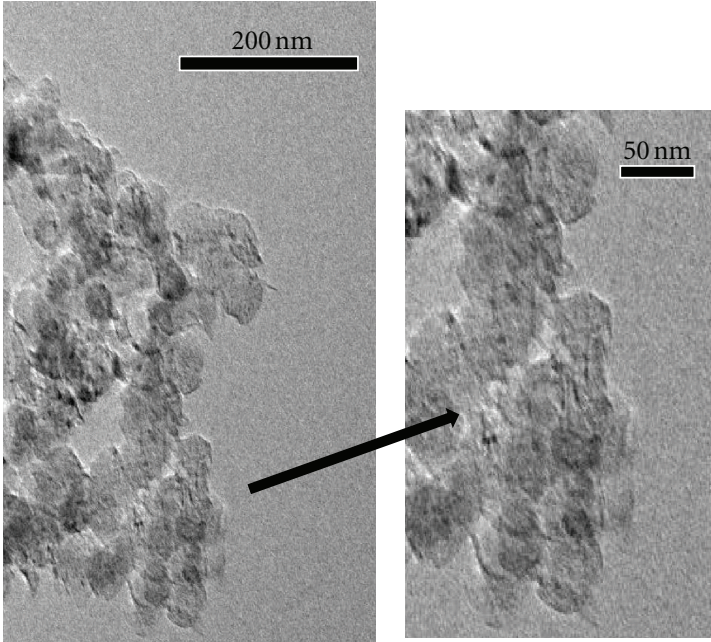

(d)

(c)

FIGURE 3: HRTEM micrographs of carbon aerogels. The displayed scale bars are (a, b, c) $200 \mathrm{~nm}$ and (d) $50 \mathrm{~nm}$. 


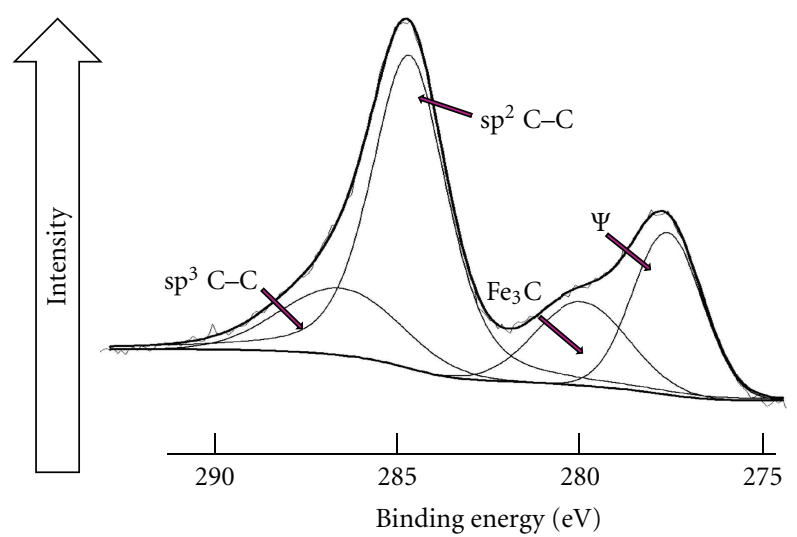

(a)

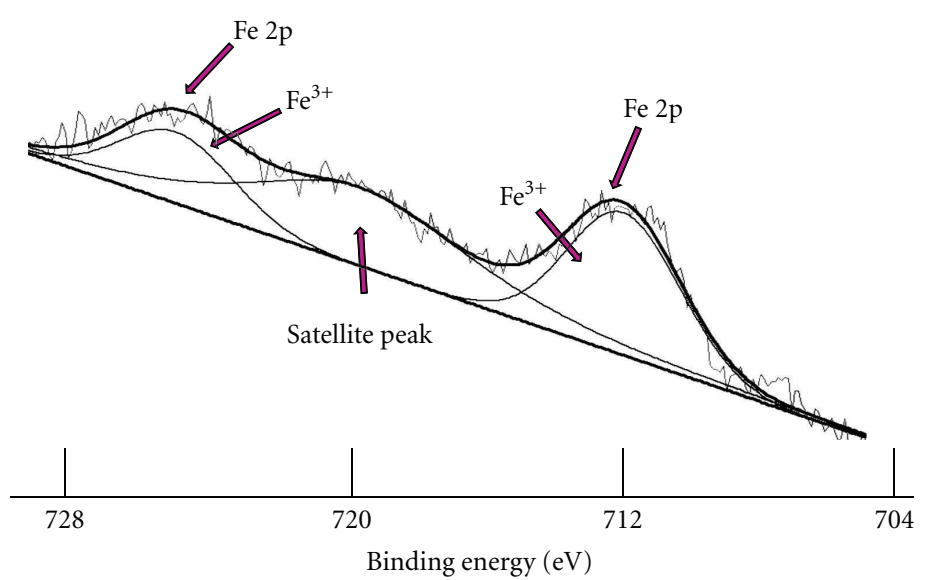

(b)

FIGURE 4: XPS spectra of carbon aerogels: (a) C 1s region, and (b) Fe $2 p$ region.

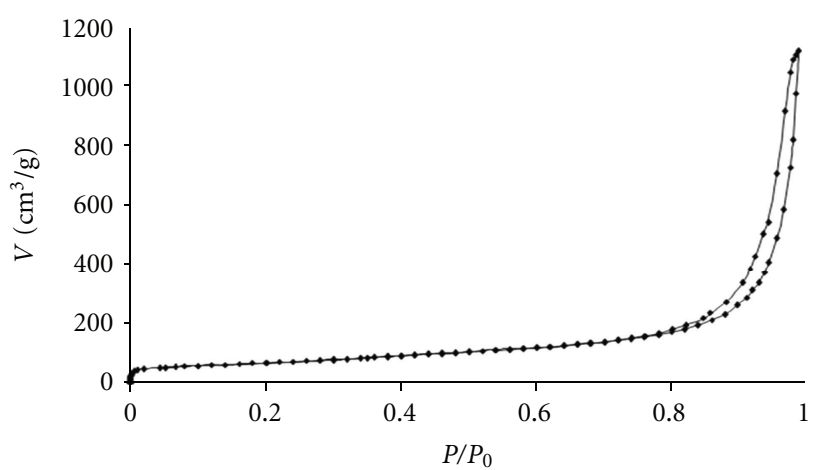

Figure 5: $\mathrm{N}_{2}$ adsorption isotherm type IV $(77 \mathrm{~K})$ of Carbon Aerogels.

$[21,22]$, normally used as carbon source organic gases or vapors (hydrocarbons, alcohols, etc.). It has been much less employed for carbon nanotube preparation as the sole source of catalyst and carbon [23]. In the present work it is proposed a simple CCVD methodology for the synthesis of carbon aerogels uses ferrocene as source of both Fe catalyst and of carbon filler material. The proposed method is simpler than the usually employed synthesis through organic aerogels, which involves several steps under conditions varying in an ample range. A key procedure in the methodology reported is the division in two consecutive steps of the evaporation of the ferrocene, with a short time in between the two evaporation steps. This way, a two-phase system is generated, with imperfections in carbon nanotubes, which couple with nanocapsules of carbon nanotubes produced in the second step, finally leading to the carbon aerogels.

\section{Conclusions}

Using the CCVD method and ferrocene as the starting material, carbon aerogels with surface areas and pore volumes of $780 \pm 20 \mathrm{~m}^{2} / \mathrm{g}\left(S_{\mathrm{BET}}\right)$ and of $0.55 \pm 0.02 \mathrm{~cm}^{3} / \mathrm{g}\left(V_{\mathrm{BJH}}\right)$, respectively, are obtained. The large surface area is not due to microspores but to mesopores formed by the aggregation of carbon nanostructures. These porous properties are promising features for applications in the physisorption of gases, for example, in the storage of molecular hydrogen for fuel cell applications. The XPS tests revealed the presence of iron carbide and the partial oxidation of carbon nanostructures.

\section{Acknowledgments}

The authors thank PDVSA-INTEVEP for HRTEM assays, Surface Physicochemistry Laboratory at IVIC for XPS measurements, and Carbon Laboratory at USB for $\mathrm{N}_{2}$ physisorption measurements.

\section{References}

[1] D. Mann, "Synthesis of carbon nanotubes," in Carbon Nanotubes: Properties and Applications, M. J. O'Connell, Ed., Taylor \& Francis, Boca Raton, Fla, USA, 2006.

[2] F. Hennrich, C. Chan, V. Moore, M. Rolandi, and M. O'Connell, "The element carbon," in Carbon Nanotubes Properties and Applications, M. J. O'Connell, Ed., Taylor \& Francis, Boca Raton, Fla, USA, 2006.

[3] C. J. Gabelich, T. D. Tran, and I. H. Suffet, "Electrosorption of inorganic salts from aqueous solution using carbon aerogels," Environmental Science and Technology, vol. 36, no. 13, pp. 3010-3019, 2002.

[4] J. M. Miller and B. Dunn, "Morphology and electrochemistry of ruthenium/carbon aerogel nanostructures," Langmuir, vol. 15, no. 3, pp. 799-806, 1999.

[5] H. Y. Tian, C. E. Buckley, S. Mulè, M. Paskevicius, and B. B. Dhal, "Preparation, microstructure and hydrogen sorption properties of nanoporous carbon aerogels under ambient drying," Nanotechnology, vol. 19, no. 47, Article ID 475605, 2008.

[6] A. M. Shariff, D. M. Beshir, M. A. Bustam, and S. Maitra, "Some studies on the synthesis and characterization of carbon aerogel," Transactions of the Indian Ceramic Society, vol. 69, no. 2, pp. 1-4, 2010. 
[7] M. Kumar and Y. Ando, "Chemical vapor deposition of carbon nanotubes: a review on growth mechanism and mass production," Journal of Nanoscience and Nanotechnology, vol. 10, no. 6, pp. 3739-3758, 2010.

[8] Ç. Öncel and Y. Yürüm, "Carbon nanotube synthesis via the catalytic CVD method: a review on the effect of reaction parameters," Fullerenes Nanotubes and Carbon Nanostructures, vol. 14, no. 1, pp. 17-37, 2006.

[9] R. Fu, M. S. Dresselhaus, G. Dresselhaus et al., "The growth of carbon nanostructures on cobalt-doped carbon aerogels," Journal of Non-Crystalline Solids, vol. 318, no. 3, pp. 223-232, 2003.

[10] S. A. Steiner III, T. F. Baumann, J. Kong, J. H. Satcher Jr, and M. S. Dresselhaus, "Iron-doped carbon aerogels: novel porous substrates for direct growth of carbon nanotubes," Langmuir, vol. 23, no. 9, pp. 5161-5166, 2007.

[11] S. Huang, L. Dai, and A. W. H. Mau, "Patterned growth and contact transfer of well-aligned carbon nanotube films," Journal of Physical Chemistry B, vol. 103, no. 21, pp. 42234227, 1999.

[12] Y. M. Shulga, T. C. Tien, C. C. Huang et al., "XPS study of fluorinated carbon multi-walled nanotubes," Journal of Electron Spectroscopy and Related Phenomena, vol. 160, no. 13, pp. 22-28, 2007.

[13] K. Y. Yang, X. Wei, Y. Zheng, W. T. Zhang, and X. Wang, "Synthesis and characteristics of $\mathrm{Fe}_{3} \mathrm{C}$ nanoparticles embedded in amorphous carbon matrix," Chemical Research in Chinese Universities, vol. 26, no. 3, pp. 348-351, 2010.

[14] K. Y. Chun, S. K. Choi, H. J. Kang, C. Y. Park, and C. J. Lee, "Highly dispersed multi-walled carbon nanotubes in ethanol using potassium doping," Carbon, vol. 44, no. 8, pp. 14911495, 2006.

[15] http://www.lasurface.com/, 2012.

[16] Y. Sun, X. Ding, Z. Zheng, X. Cheng, X. Hu, and Y. Peng, "Magnetic separation of polymer hybrid iron oxide nanoparticles triggered by temperature," Chemical Communications, no. 26, pp. 2765-2767, 2006.

[17] V. C. H. Kroll, P. Delichure, and C. Mirodatos, "Methane reforming reaction with carbon dioxide over a $\mathrm{Ni} / \mathrm{SiO}_{2}$ catalyst: the nature of the active phase," Kinetics and Catalysis, vol. 37, no. 5, pp. 698-705, 1996.

[18] A. De Stefanis, S. Kaciulis, and L. Pandolfi, "Preparation and characterization of Fe-MCM-41 catalysts employed in the degradation of plastic materials," Microporous and Mesoporous Materials, vol. 99, no. 1-2, pp. 140-148, 2007.

[19] S. J. Gregg and K. S. W. Sing, "The physical adsorption of gases by mesoporous solids: the type IV isoteherm," in Adsorption, Surface Area and Porosity, SegundaEdición, Madrid, Spain, Academic Press, New York, NY, USA, 1982.

[20] Q. H. Yang, P. X. Hou, S. Bai, M. Z. Wang, and H. M. Cheng, "Adsorption and capillarity of nitrogen in aggregated multiwalled carbon nanotubes," Chemical Physics Letters, vol. 345, no. 1-2, pp. 18-24, 2001.

[21] H. W. Zhu, C. L. Xu, D. H. Wu, B. Q. Wei, R. Vajtai, and P. M. Ajayan, "Direct synthesis of long single-walled carbon nanotube strands," Science, vol. 296, no. 5569, pp. 884-886, 2002.

[22] A. Moisala, A. G. Nasibulin, D. P. Brown, H. Jiang, L. Khriachtchev, and E. I. Kauppinen, "Single-walled carbon nanotube synthesis using ferrocene and iron pentacarbonyl in a laminar flow reactor," Chemical Engineering Science, vol. 61, no. 13, pp. 4393-4402, 2006.
[23] A. Barreiro, S. Hampel, M. H. Rümmeli et al., "Thermal decomposition of ferrocene as a method for production of single-walled carbon nanotubes without additional carbon sources," Journal of Physical Chemistry B, vol. 110, no. 42, pp. 20973-20977, 2006. 

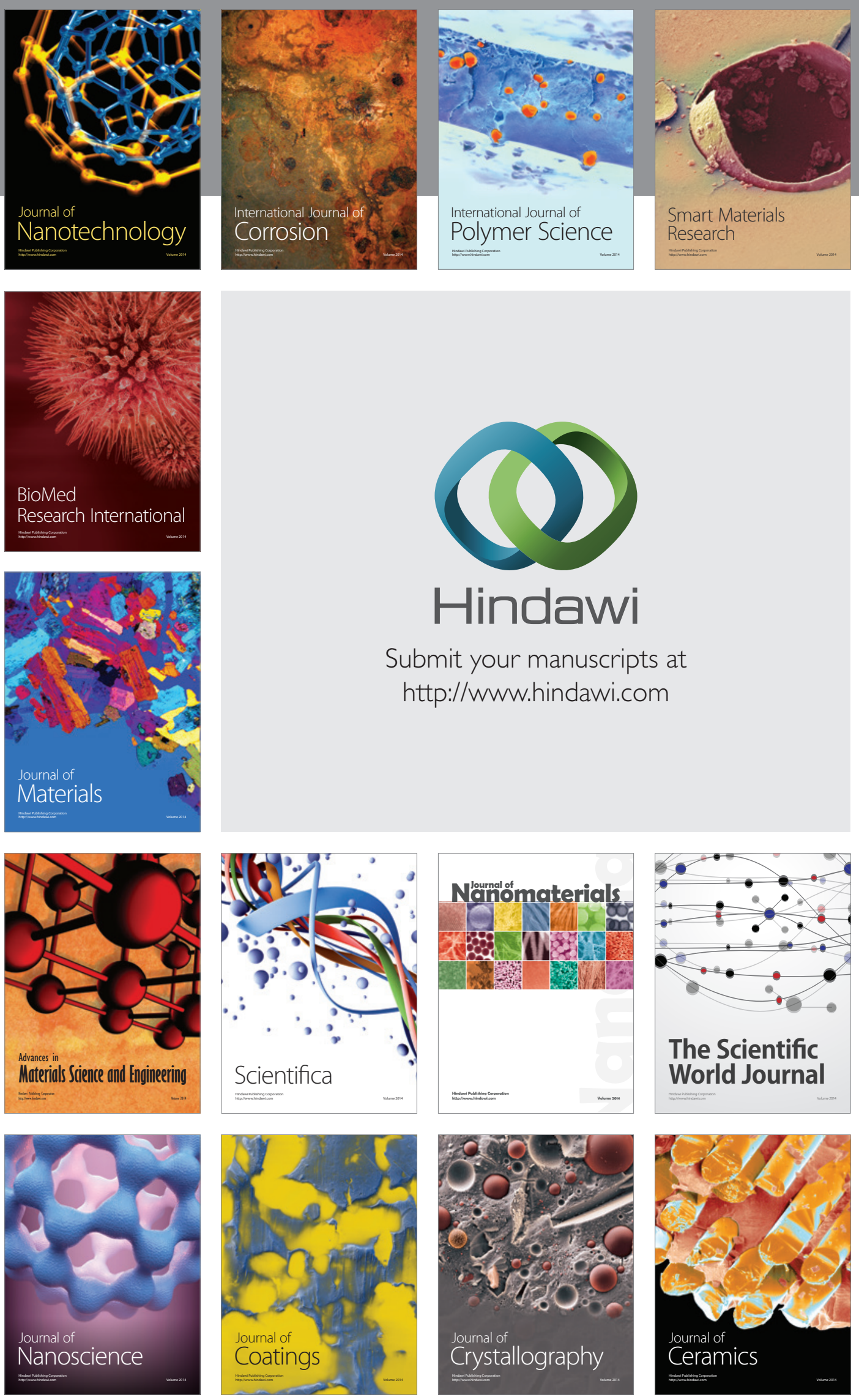

The Scientific World Journal

Submit your manuscripts at

http://www.hindawi.com

\section{World Journal}

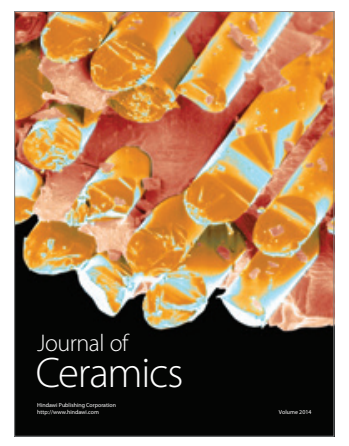

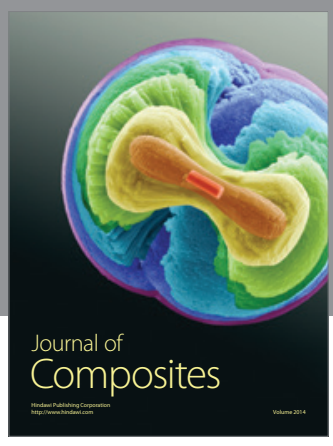
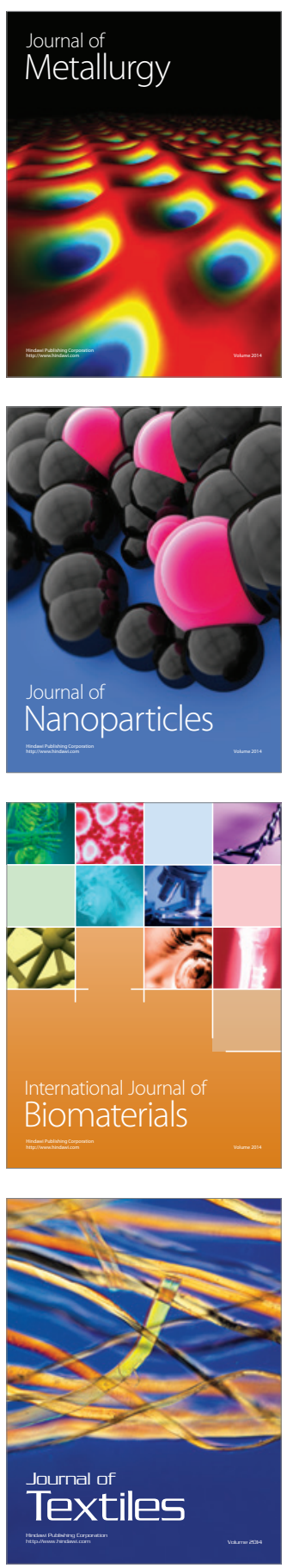